\title{
Localization of City Park Using AHP in GIS, Case Study: District 8 of Isfahan, Isfahan, Iran
}

\author{
Zahra Qasemy ${ }^{1}$, Kaveh Ostad-Ali-Askari ${ }^{2}$, Saeid Eslamian ${ }^{3}$, Vijay P. Singh ${ }^{4}$, \\ Nicolas R. Dalezios ${ }^{5}$, Mohammed Matouq ${ }^{6}$ \\ ${ }^{1}$ Department of Remote Sensing, Yazd Branch, Islamic Azad University, Iran. \\ $2^{2 *}$ Department of Civil Engineering, Isfahan (Khorasgan) Branch, Islamic Azad University, Isfahan, Iran. \\ ${ }^{3}$ Department of Water Engineering, Isfahan University of Technology, Isfahan, Iran. \\ ${ }^{4}$ Department of Biological and Agricultural Engineering \& Zachry Department of Civil Engineering, Texas A \\ and M University, 321 Scoates Hall, 2117 TAMU, College Station, Texas 77843-2117, U.S.A. \\ ${ }^{5}$ Laboratory of Hydrology, Department of Civil Engineering, University of Thessaly, Volos, Greece \& \\ Department of Natural Resources Development and Agricultural Engineering, Agricultural University of \\ Athens, Athens, Greece. \\ ${ }^{6}$ Al-Balqa Applied University, Chemical Engineering Department, President of Jordan Japan Academic Society, \\ JJAS, P.O. Box 4486, Amman 11131-Jordan.
}

*Corresponding Author: Kaveh Ostad-Ali-Askari, Department of Civil Engineering, Isfahan (Khorasgan) Branch, Islamic Azad University, Isfahan, Iran.

\begin{abstract}
Nowadays, daily life intensively depends on public services. Increasing population and urbanization take humans away from environment which may lead to chaos in usage of city lands. Consequently, human is in trouble using public services and facilities including green spaces. Isfahan, one of the metropolitans, has $18 \mathrm{~m} 2$ green spaces per person while city park of district 8 is of inappropriate distribution with regard to population density. The current study is aimed to localize a suitable place for city park which focuses on such criteria as:
\end{abstract}

- To be close to street

- To be close to residential centers

- To be far away from the existing parks

- Tobe close to cultural and educational centers

- To be close to parking lot

Finally, GIS has been used to create given layers and calculate weights based on AHP. According to overlap between layers, the most appropriate places have been identified:

1. In Marchin district which is of the area of $16 \mathrm{~m}^{2}$

2. In Bariman district which is of the area of $29 \mathrm{~m}^{2}$

3. In Imam Komeini street which is of the area of $17 \mathrm{~m}^{2}$

4. In Jaber Ansari street which is of the area of $23 \mathrm{~m}^{2}$

Keywords: City Park, Geographical Information System (GIS), AHP, Localization, District 8 of Isfahan

\section{INTRODUCTION}

Among the most important problems of Isfahan District 8, we can point to inappropriate distribution, unavailability and few number of city parks with regard to area of the district and population density. Spatial organization, optimized distribution and balanced green spaces are of significance for meeting welfare of the population. Industry development and expansion of urbanization may lead to harmful outcomes affecting city and urbanization. Public sectors are the most significant components of cities 
and urbanization. Accordingly, humans are submerged in frequent interactions. One of the most notable elements can be green spaces and city parks which play active roles in community health.

Saberi et al. studies different uses of the given region. They concluded that AHP is the ideal method to obtain positive results. Hossainzadeh et al. conducted a study on the importance of resource management in different aspects of development plan. They found the usefulness of GIS in forestry plans. Hataminejad et al. evaluated green spaces per capita for Mashhad. They proposed a good model for Mashhad green spaces. Teymouri et al. focused on the usefulness of Iconos pictures and aerial images in obtaining information about green spaces and in calculating green spaces per capita for west-north of Tehran. Finally, they prioritized places for green spaces $^{14}$. There are various publications related to green spaces such as green spaces and their positive effects on mental health by reducing air pollution and producing oxygen as well as controlling winds (Majnoonian, 1995). The most attractive point about green spaces is that it leads to mental safety. Additionally, it is the most active factor in reducing air pollution. Green spaces can link isolated human to environment. Also, it meets aesthetic needs of city population. As for hygiene, environmental and social-mental needs, green spaces can be taken as useful resources. To this end, according to social justice, every social class must be provided with equality in access to green spaces and city parks for their free times. It is not fair that high social class and rich population choose residential places with dense green spaces and spectacular views ${ }^{4}$. GIS is of use in city plans for appropriate use distribution. To this end, AHP is used to fins the most realistic results.

\section{STUDIES REgION}

To create a localization map of civil park, Isfahan district 8 has been selected. The selected district delimits to Baharestan in north and to Kaveh street in west and to Shahid Forouqi in south and to Imam Komeini street in west-south (Figure 1). The given district is of the area of 2039 acres (230 acres are old textures) out of the Isfahan total area of 18370 acres. Additionally, if each vehicle is designated a space of $25 \mathrm{~m}$, the least pace required for parking lot will be of $8050 \mathrm{~m}^{2}$. Also, districts 8 and 16 had a population of 248782 in 2011 [1-14].

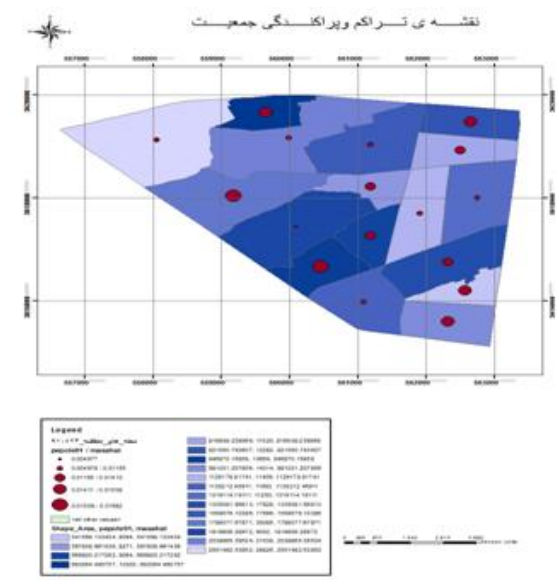

Figure1. Distribution and density of population

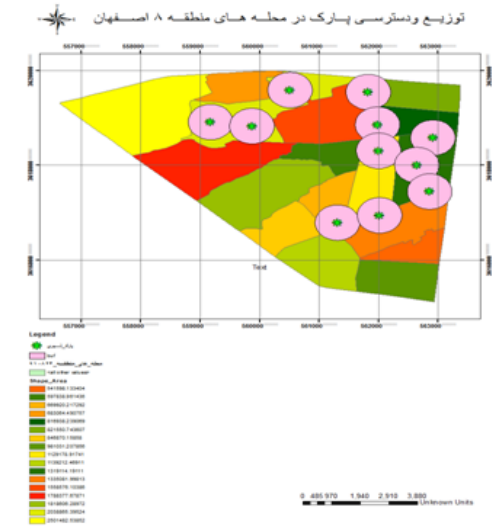

Figure2. Distribution and access to city parks of district 8 


\section{MeThodology}

The current study is of analytical-descriptive nature conducted to localize city park of Isfahan district 8. Descriptive studies have been conducted based on documents, library resources and referring to related organizations. Analysis has been done using GIS and AHP. Those layers which are more suitable for City Park are advocated higher weights while those layers which are not suitable for City Park are designated fewer weights. Required layers are translated into RASTER in GIS environment based on valued measures. They are reclassed for categorization based on RECLASS. SUM WEIGHT was used to compare results and enforce finalized weights in AHP. The resultant layer was categorized into 6 classes to identify preferred locations for City Park.

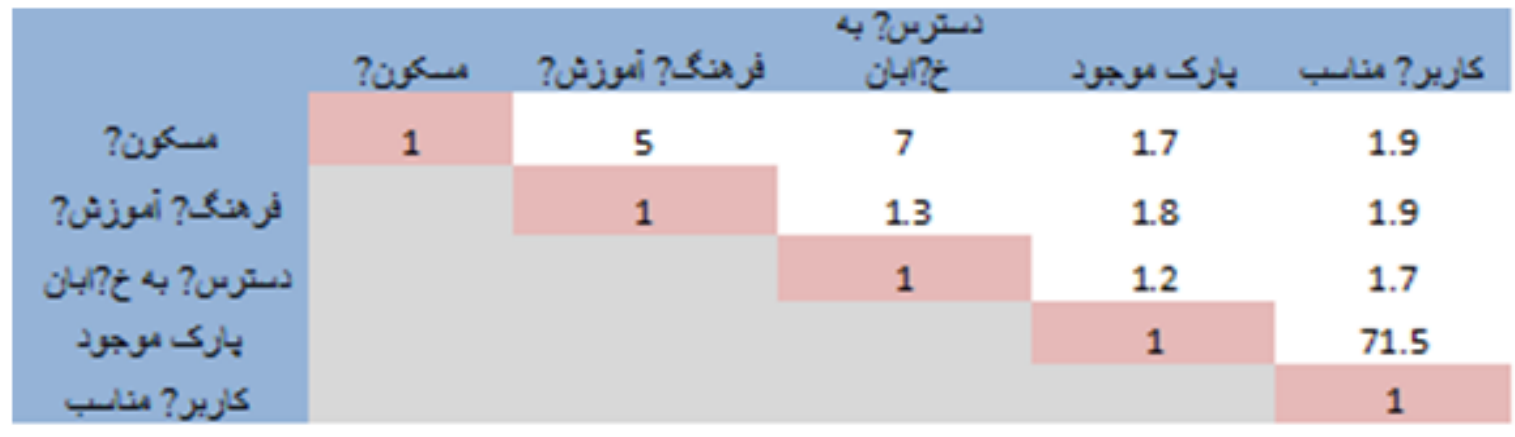

Figure3. Matrix of evaluated measures

\subsection{Closeness to Residential Centers}

Parks are good places for all age-groups for spending free times there. They should be close to residential centers in order to save time and money. Parks are aesthetic component of city face which can play role in reducing air pollution [15-29].

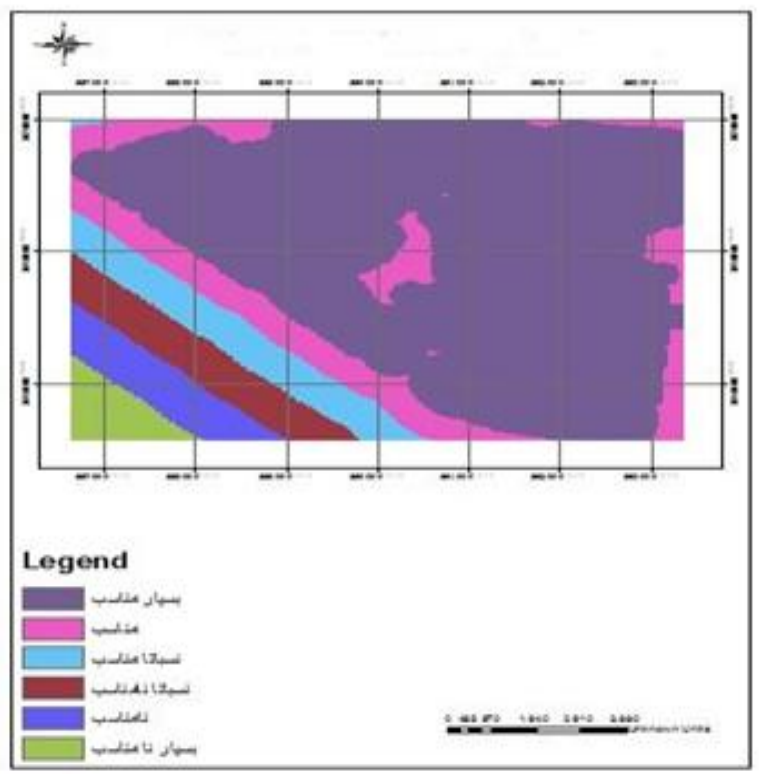

Figure4. Closeness to residential centers

According to positive effects of green paces and parks and their role in reducing acoustic and air pollution, it is required to have these kinds of places all over the cities. According to the fact that parks are appropriate places for free times and for establishment of cultural and educational centers, they are designated high weights (figure 5) [30-46].

\subsection{Access to Communication Network}

For parks to be at easy access, communication networks are required. To meet safety and availability of parks, it is preferred to have all-side communication network. Accordingly, communication network is taken as fitted layer which is assigned high weight (figure 5). 


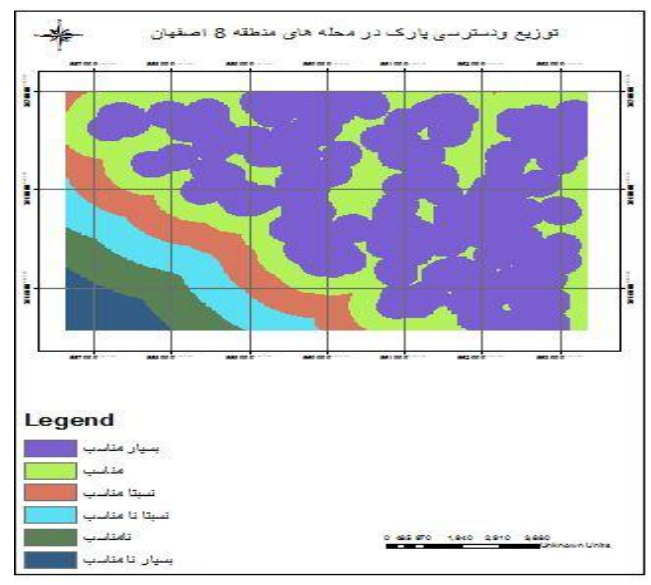

Figure5. Access to communication network

\subsection{Appropriate Uses}

An appropriate land for establishment of park is a place where no previous construction has been done. Additionally, it should be a place with spectacular view laden with green spaces, waterfalls and rivers. The studies place has no river but it is full of green spaces. The old inexpensive lands available in the given region makes the place a good one for city park which consequently acquires a high weight (figure 6) [47-50].

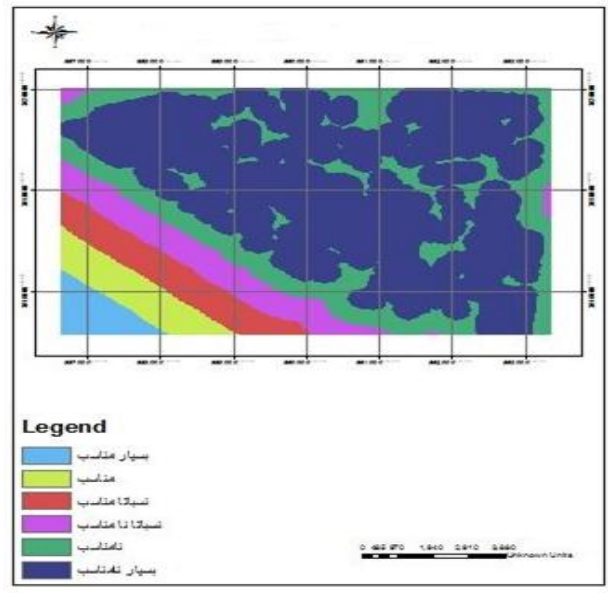

Figure6. Appropriate uses

\subsection{Distance from the Existing Parks}

To precisely localize city parks, it is necessary to keep their interval. Accordingly, those places with acceptable interval are given high weights (figure 7).

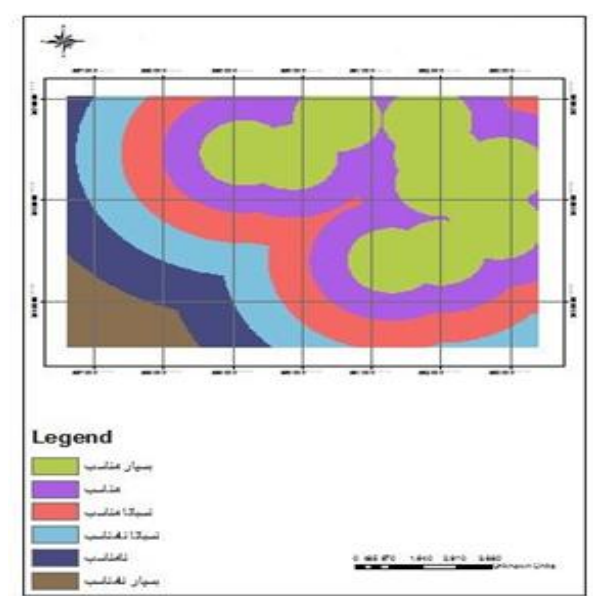

Figure7a. Appropriate uses 


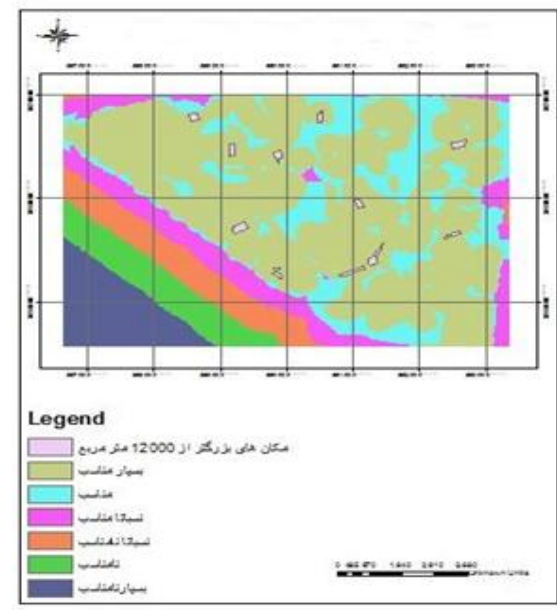

Figure7b. Distance from the existing parks

\section{RESUltS AND RECOMMENDATIONS}

According to binary comparative weighing method, measures are compared to identify the most important pair. Then, a matrix is formed inputs of which are predefined weights and outputs are relative weights (Malsczoki, 1999). After given layers have been weighed in AHP, weight of each layer is dedicated according to the following table. Layers are translated into RASTER and then recategorized by RECLASS using SUM WEIGHT in order to enforce the calculated weights based on AHP. Layers are summed and the optimized place for City Park is identified (figure 8).

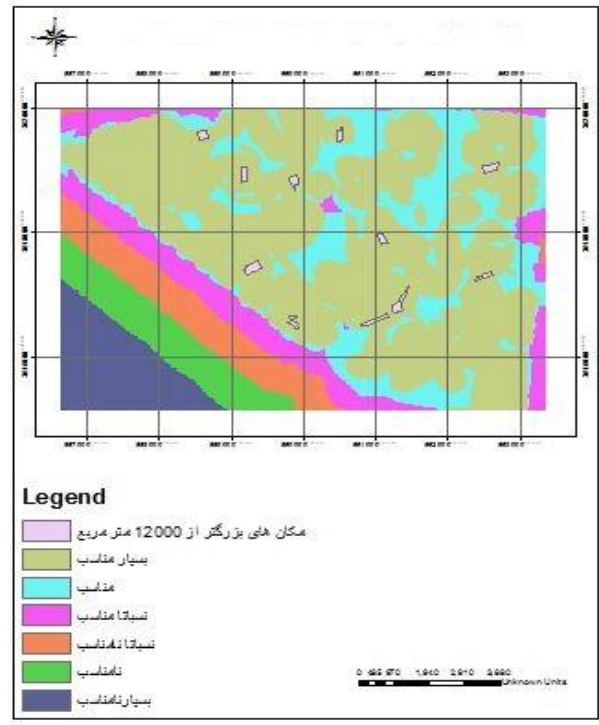

Figure8. Appropriate places after overlapping

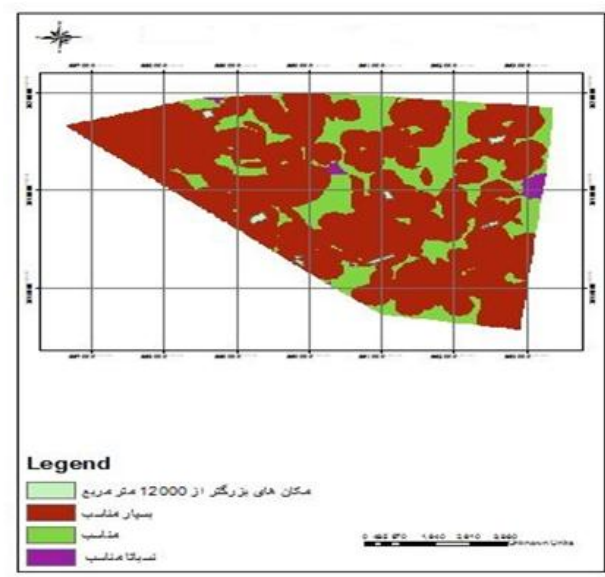

Figure9. Appropriate places based on the requirement of a land of at least $12000 \mathrm{~km}$ 


\section{CONCLUSION}

According to figure 2, distribution of city parks in Isfahan District 8 is not acceptable. The main focus is on some places including Khane Isfahan, Mir Emad, Shahriyar, and Jaber Ansari. Other neighborhoods do not have any city park. According to the current study and the requirement of at least a land of $12000 \mathrm{~km}$, some places are eligible:

- Marchin district which is of the area of $16 \mathrm{~m}^{2}$

- Bariman district which is of the area of $29 \mathrm{~m}^{2}$

- Imam Komeini street which is of the area of $17 \mathrm{~m}^{2}$

- Jaber Ansari street which is of the area of $23 \mathrm{~m}^{2}$

\section{REFERENCES}

[1] Ahmadi, A. Movahed, A. Shojaeian, A. introduction of optimized localization pattern of green spaces using GIS or AHP: case study: Ahvaz district 7. Amayesh-e Mohit quarterly magazine. Vol. 15. 2010

[2] Pour Ahmad, A. Akbarpour Saraskanrood, A. M. Sotoudeh, S. 2009. Management of city green spaces, Municipality of Tehran, district 9. Human geography research. Vol. 69

[3] Hosseini Nasr, Seyyed Mohammd. Rezvnfar, Masumeh. Owladi, Jafar. Sharifi, Morteza. City parks as recreation places based on GIS: case study: Chitgr forest park, Tehran.

[4] Zangi Abadi, A. Mokhtari Malek Abadi. 2005. Cities, green spaces and refreshed attitude towards humanistic aspect of city plans. Payam-E sabz monthly magazine. Vol. 87:42

[5] Ziary, K. 2002. Khoram Abbad in human geography. Publication: Fadak-E khoram Abbad

[6] Sadnia, 2000. Green book of municipalities. Vol. 9. City research and planning department. Publication: Vzarat-E Keshvar

[7] Saberi, A. Qanbari, A. Hossenzadeh, M. localization of city parks and green spaces uing GIS and multifactorial AHP, case study: Shushtar. Jeomatic international conference

[8] Majnoonin, Henric. 1995. Discussion on parks, green spaces and recreation resorts. Public services, parks and green spaces department, Tehran.

[9] Mohammadi, J. Mohammadi Deh Cheshmeh, M. Yeganeh. 2007. Qualitative evaluation of the role of city green spaces and their optimized uses in Shahrekord. Ecology. Vol. 44:98

[10] Mohammdi, J. 2001. Geographic information website for localization of city green spaces. Publication: Shahrdariha. Vol. 44:15

[11] Mohammadi, J. Zarabi, A. Pour Qayoumi, H. spatial analysis and localization of city parks, case study: Kazeroun. Research journal of geography and planning (Tabriz University). $16^{\text {th }}$ Year. Vol. 38. Winter of 1390. Pp 123-152.

[12] Mohammdi, J. 2002. Analysis of spatial distribution and spatial localization for two districts of Tabriz. M.A. thesis. Shahid Beheshti University (Kazeroun).

[13] Revision map of uses for Isfahan district 8

[14] 1.2000 map of the year of 200, Isfahan district 8

[15] Optimized localization of parks and green spaces using GIS.

Citation: Z. Qasemy et.al., "Localization of City Park Using AHP in GIS, Case Study: District 8 of Isfahan, Isfahan, Iran", International Journal of Constructive Research in Civil Engineering, 4(2), pp. 15-20. DOI: http://dx. doi.org/10.20431/2454-8693.0402003

Copyright: (0) 2018 Z. Qasemy et.al., This is an open-access article distributed under the terms of the Creative Commons Attribution License, which permits unrestricted use, distribution, and reproduction in any medium, provided the original author and source are credited. 